\title{
The Expression and Clinical Significance of
} Programmed Cell Death Receptor 1 and Its Ligand in Tumor Tissues of Patients with Extranodal Nasal NK/T Cell Lymphoma

\author{
Yu Feng \\ West China Hospital of Sichuan University \\ Xia Feng \\ The Public Health Clinical Center of Chengdu \\ Caixia Jing \\ West China Hospital of Sichuan University \\ Xinmei Yu \\ West China Hospital of Sichuan University \\ Caigang Xu ( $\nabla$ xucaigang@wchscu.cn ) \\ West China Hospital of Sichuan University
}

\section{Research Article}

Keywords: Extranodal natural killer/T-cell lymphoma, programmed cell death receptor 1, programmed cell death ligand 1, disease staging, treatment response assessment.

Posted Date: June 23rd, 2021

DOl: https://doi.org/10.21203/rs.3.rs-601816/v1

License: (c) (i) This work is licensed under a Creative Commons Attribution 4.0 International License.

Read Full License

Version of Record: A version of this preprint was published at Scientific Reports on January 7th, 2022. See the published version at https://doi.org/10.1038/s41598-021-02515-5. 


\section{Abstract}

Appropriate biomarkers may help distinguish the biological behavior of different types of lymphoma and their response to traditional chemotherapy. Extranodal natural killer/T-cell lymphoma (ENKTL) and diffuse large B-cell lymphoma(DLBCL) belong to different subtypes of non-Hodgkin's lymphoma, the biological behavior and prognosis of them are very different, programmed cell death receptor 1 (PD-1) and its ligand (PD-L1) have been investigated in these two types of diseases. However, few studies addressed the difference of PD-1/PD-L1 levels between ENKTL and DLBCL, in order to find out the difference and related clinical application value, the clinical data and tumor tissue paraffin sections of 24 newly diagnosed ENKTL patients and 42 newly diagnosed diffuse large B-cell lymphoma (DLBCL) were collected. PD-1/PD-L1 levels in tumor tissues were detected by immunohistochemical staining. The relationship between the PD-1/PD-L1 levels and clinical data of patients with ENKTL patients was analyzed. Both patient groups showed PD-1 level in tumor tissue of ENKTL patients was significantly lower than that of DLBCL patients $(P<0.05)$, while the PD-L1 level in tumor tissues of ENKTL patients was not different from DLBCL $(P<0.05)$. In addition, the ENKTL patients with $B$ symptoms, elevated lactate dehydrogenase (LDH) levels and decreased hemoglobin (HGB) concentrations had lower level of PD-1 in tumor tissue. PD-L1 level in tumor tissues, the LDH level, Epstein-Barr genome (EBV-DNA) copy and Ki-67 index may affect the efficacy of ENKTL patients $(P<0.05)$, but they were not independent factors. PD-L1 levels in tumor tissues has clinical significance in ENKTL patients, which suggested that the PD-1/PD-L1 signal pathway may be involved in the immune escape of ENKTL and play different roles in different lymphoma subtypes.

\section{Introduction}

Extranodal NK/T-cell lymphoma, nasal type (ENKTL) is an aggressive non-Hodgkin lymphoma which originates from $\mathrm{T}$ cell or NK-like cell, it often involve the nasal cavity, face and upper respiratory tract. Compared to diffuse large B-cell lymphoma (DLBCL), this disease is characterized by more difficult diagnosis, higher malignant, rapider progress, and easier to be resistant to traditional chemotherapy. Therefore, there is currently no standard treatment plan for ENKTL ${ }^{[1]}$. The above characteristics are probably related to tumor cells evading the immune response of the body, the signaling pathway involving programmed cell death receptor 1 (PD-1) is likely one mechanisms of immune evasion ${ }^{[2]}$.

Existing studies have shown that PD-1 is mainly expressed on CD $4+$ or $C D 8+T$ cell membranes, and it has two types of ligands, which are PD-L1 and PD-L2. PD-L1 is the main ligand of PD-1 in the human body, PD-L1 is expressed in not only immune cells such as activated lymphocytes, NK cells and macrophages, but also tissue cells such as lung and vascular endothelium ${ }^{[2]}$. What is more, it is expressed at high levels in tumor cells, such as melanoma ${ }^{[3]}$, gastric cancer ${ }^{[4]}$, kidney cancer ${ }^{[5]}$, high levels of PD-L1 expressed on tumor cells can inhibit the proliferation and activation of lymphocytes by interacting with PD-1 on lymphocytes to achieve the immune escape of tumor cells ${ }^{[2]}$. Recent studies have shown that PD-L1 level in nasal biopsy tissues of ENKTL patients is much higher than that of 
rhinitis patients ${ }^{[6]}$. Based on the above background, we used a retrospective case-control study to analyze the differences in PD-1/PD-L1 levels in tumor tissues of between ENKTL and DLBCL patients.

Therefore we examined PD-1/PD-L1 in tumor tissues of ENKTL and DLBCL patients. Our results show that PD-1/PD-L1 level in tumor tissues of ENKTL patients are useful for ENKTL staging and prediction of treatment response. The same results were not obtained for patients with DLBCL, another type of lymphoma, suggesting that the biomarker may show some specificity for ENKTL.

\section{Materials And Methods}

\section{Study population and treatment}

This retrospective study included 24 cases of ENKTL (18 males, median age 49.5 years) diagnosed in West China Hospital of Sichuan University from December 2017 to December 2018 and 42 cases of DLBCL patients, and pathological paraffin sections of all 66 patients have been obtained from the Department of Pathology, West China Hospital, Sichuan University. The diagnostic criteria are based on the 2008 WHO classification criteria for hematopoietic and lymphoid tissue tumors ${ }^{[7]}$. The efficacy evaluation after two courses of chemotherapy follows the "Evaluation Criteria for the Efficacy of Malignant Lymphoma", including complete remission (CR), partial remission (PR), stable disease (SD) and disease progression (PD) ${ }^{[8]}$. We have signed an informed consent form with all research subjects, and have been approved by the Ethics Committee of West China Hospital of Sichuan University. All methods are performed in accordance with the relevant guidelines and regulations.

\section{Immunohistochemical staining (IHC) for PD-1/PD-L1}

Paraffin-embedded sections (3um) were used for immunohistochemical staining (IHC). After being dewaxed and hydrated, they were incubated with a 1:75 dilution of PD-L1 antibody [28 - 8] (Abcam, Cambridge, UK) / PD-1 antibody (Zhongshan Jinqiao, Beijing, China). IHC was accomplished by avidinbiotin peroxidase complex detection system. The percentage of PD-1/PD-L1 expression (the number of cells stained with membranes in the total number of tumor cells) was analyzed by Image $\mathrm{J}$ software. The percentage $>30 \%$ was defined as PD-L1 (+), while the percentage $>5 \%$ was considered PD-1 (+) ${ }^{[9]}$.

\section{Statistical analyses}

PD-1/PD-L1 level in tumor tissues are presented as the median and interquartile range [M(IQR)]. The Kruskal-Wallis test was used to analyze the differences between groups, and the Mann-Whitney $U$ test and Spearman rank correlation analysis were used to analyze the relationship between PD-1/PD-L1 level in tumor and the clinical data of patients. Fish test and Logistic regression were used to conduct univariate and multivariate analysis of predictors of treatment response in ENKTL patients. We set $P$ value $<0.05$ as the significant difference.

\section{Results}




\section{Baseline clinical characteristics of patients}

Baseline clinical characteristics of 24 patients with ENKTL and 42 ones with DLBCL are summarized in Table 1. In the ENKTL group, 7 (29\%) was in stage III-IV, and 8 (33\%) had LDH > 250 U/L. 23 (88\%) patients accepted anthracycline-containing chemotherapy regimens. All patients received at least two cycles of chemotherapy before radiotherapy. After two courses of chemotherapy, 8 patients (33\%) achieved CR. 
Table 1

Baseline and clinical characteristics of 66 patients

\section{Characteristics}

Age, year

$>60$

$\leq 60$

Sex

male

female

Ann Arbor Stage

H-II

III-IV

Bulky mass

Yes

No

B symptoms

Yes

No

Extranodal sites

$>1$

$\leq 1$

ECOG PS

$\geq 1$

$<1$

Bone marrow involvement

Yes

No

Values are $\mathrm{n}(\%)$.

DLBCL, diffuse large B-cell lymphoma; ECOG PS, Eastern Cooperative Oncology Group performance score; ENKTL, extranodal natural killer/T-cell lymphoma; PINK-E, prognostic index of extranodal natural killer/T-cell lymphoma; IPI, international prognostic index; "-", data not collected.

ENKTL patients $(n=24) \quad$ DLBCL patients $(n=42)$
$5(21)$

$19(79)$

$18(75)$

$6(25)$

$17(71)$

$7(29)$

$1(4)$

$23(96)$

$14(58)$

$10(42)$

20 (83)

4 (17)

4 (17)

20 (83)

32(71)

1 (4)

23 (96)
40(95)
2(5)
11(26)

12(29)

18(43)

24(57)

19(45)

23(55)

29(69)

13(31)

31(74)

15(36)

27(64)

8(19)

34(81) 


\begin{tabular}{|c|c|c|}
\hline Characteristics & ENKTL patients $(n=24)$ & DLBCL patients $(n=42)$ \\
\hline \multicolumn{3}{|c|}{ Lactate dehydrogenase (U/L) } \\
\hline$>250$ & $8(33)$ & $17(40)$ \\
\hline$\leq 250$ & $16(67)$ & $25(60)$ \\
\hline \multicolumn{3}{|l|}{$\operatorname{EBER}(+)$} \\
\hline Yes & $24(100)$ & - \\
\hline No & $0(0)$ & - \\
\hline \multicolumn{3}{|l|}{ PINK-E and IPI } \\
\hline Low $(0-2)$ & $16(67)$ & $33(79)$ \\
\hline $\operatorname{High}(\geq 3)$ & $8(33)$ & $9(21)$ \\
\hline \multicolumn{3}{|l|}{ Chemotherapy } \\
\hline Anthracycline & $21(88)$ & - \\
\hline Non-anthracyline & $3(12)$ & - \\
\hline \multicolumn{3}{|c|}{ Response after two treatment courses } \\
\hline Complete remission & $8(33)$ & - \\
\hline Other & $16(67)$ & - \\
\hline \multicolumn{3}{|l|}{ Values are $n(\%)$} \\
\hline $\begin{array}{l}\text { DLBCL, diffuse large } \\
\text { score; ENKTL, extran } \\
\text { natural killer/T-cell ly }\end{array}$ & $\begin{array}{l}\text { PS, Eastern Cooperative } \\
\text { ymphoma; PINK-E, prog } \\
\text { al prognostic index; "-", }\end{array}$ & $\begin{array}{l}\text { ology Group performance } \\
\text { c index of extranodal } \\
\text { not collected. }\end{array}$ \\
\hline
\end{tabular}

\section{PD-1 and PD-L1 levels in tumor tissues and relationships with clinical variables}

The distribution and expression of PD-1/PD-L1 in tumor tissues were investigated by immunohistochemical staining. Membranes of positive cells in tumor tissues from ENKTL and DLBCL patients were stained brown (Fig. 1). PD-L1 (+) was defined as positive cells proportion $>30 \%$ and PD-1 $(+)$ as $>5 \%{ }^{[9]}$. In 24 ENKTL patients, 19 (79\%) were PD-L1 (+) and 9 (38\%) were PD-1(+) (Fig. 2A). In 42 DLBCL patients, 25 (60\%) were PD-L1 (+) and 29 (69\%) were PD-1 (+) (Fig. 2B). PD-1 level in tumor tissues in ENKTL patients [3.50(0.00-9.75)] was significantly lower than in DLBCL patients [21.00(1.7544.00), $\mathrm{P}=0.0021$ ] (Fig. 2C), while PD-L1 level was not statistically different between ENKTL [49.50(35.25-80.00)] and DLBCL [50.50(2.50-77.00)] groups (Fig. 2D). In ENKTL patients, PD-1 level in tumor tissues were significantly lower with $B$ symptoms, higher levels of $\operatorname{LDH}(P<0.05$, Fig. 3A), and lower hemoglobin level (Spearman $r=0.6131, P=0.0014$, Fig. 3B). 


\section{Association of PD-1 or PD-L1 biomarkers with treatment response}

As shown in Table 2, Univariate analysis showed that ENKTL patients with higher levels of PD-L1 in tumor tissues $(P=0.0218)$ were more difficult to achieve $C R$, as were patients with high levels of $L D H(P=$ 0.0222), Ki-67 index ( $P=0.0304)$ and EBV-DNA copies $(P=0.0087)$. In multivariate analysis, however, no one varied significantly with treatment response. 
Table 2

Univariate and multivariate analyses to identify predictors of treatment response among ENKTL patients

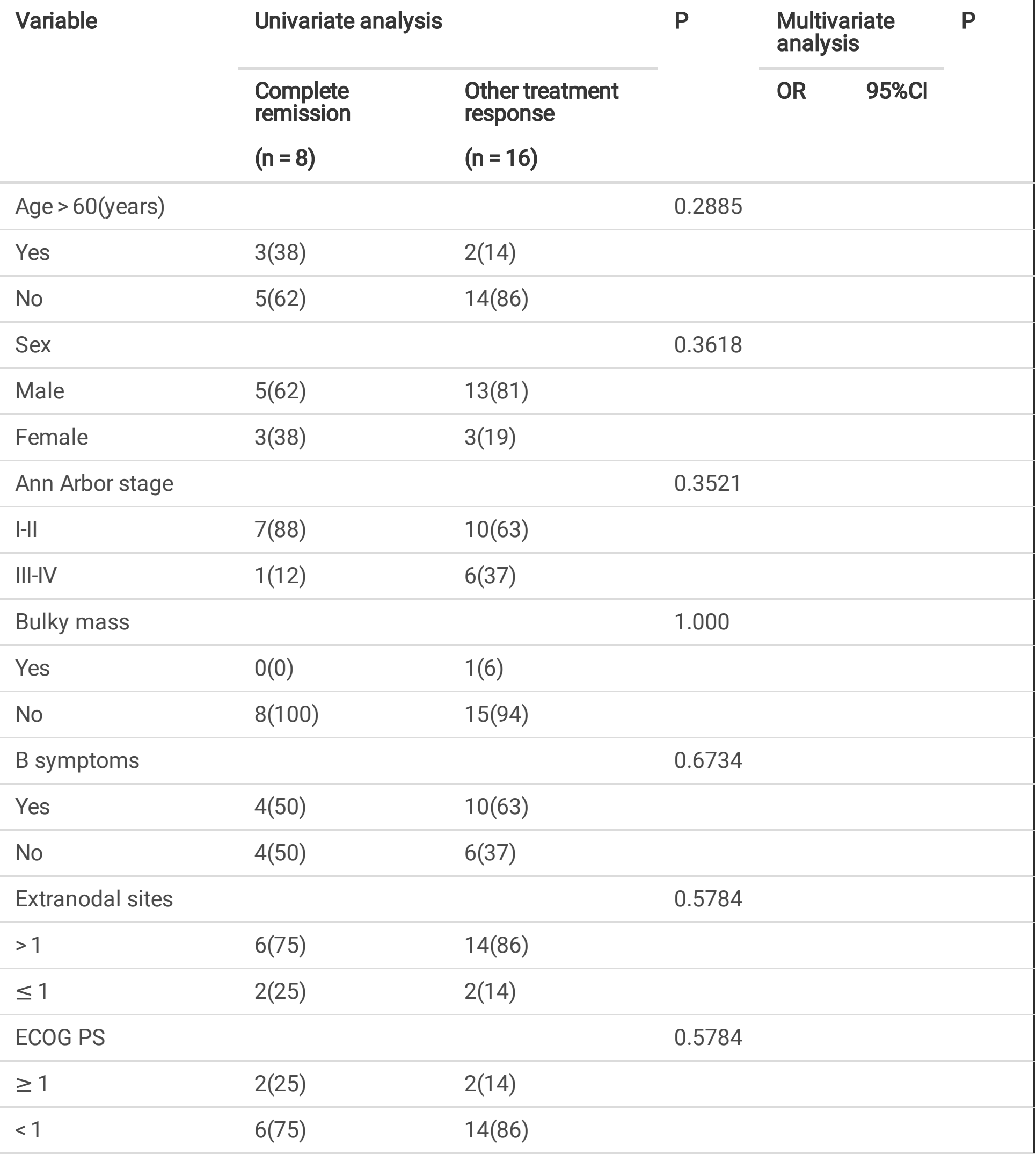

Values are $\mathrm{n}(\%)$ or median (interquartile range)

ENKTL, extranodal natural killer/T-cell lymphoma; ECOG PS, Eastern Cooperative Oncology Group performance score; PINK-E,Prognostic Index of extranodal natural killer/T-cell lymphoma; OR, odd ratio; $95 \% \mathrm{Cl}, 95 \%$ 


\begin{tabular}{|c|c|c|c|c|c|c|}
\hline \multirow[t]{3}{*}{ Variable } & \multicolumn{2}{|l|}{ Univariate analysis } & \multirow[t]{3}{*}{$\mathbf{P}$} & \multicolumn{2}{|c|}{$\begin{array}{l}\text { Multivariate } \\
\text { analysis }\end{array}$} & \multirow[t]{3}{*}{$\mathbf{P}$} \\
\hline & $\begin{array}{l}\text { Complete } \\
\text { remission }\end{array}$ & $\begin{array}{l}\text { Other treatment } \\
\text { response }\end{array}$ & & OR & $95 \% \mathrm{Cl}$ & \\
\hline & $(n=8)$ & $(n=16)$ & & & & \\
\hline $\begin{array}{l}\text { Bone marrow } \\
\text { involvement }\end{array}$ & & & 0.3333 & & & \\
\hline Yes & $1(12)$ & $0(0)$ & & & & \\
\hline No & $7(88)$ & 16(100) & & & & \\
\hline $\begin{array}{l}\text { Lactate } \\
\text { dehydrogenase > } \\
250 \mathrm{U} / \mathrm{L}\end{array}$ & & & 0.0222 & 0.972 & $\begin{array}{l}0.932 \\
\tilde{1} \\
1.014\end{array}$ & 0.187 \\
\hline Yes & $0(0)$ & $8(50)$ & & & & \\
\hline No & $8(100)$ & $8(50)$ & & & & \\
\hline PINK-E & & & 0.1893 & & & \\
\hline Low (0-2) & $7(88)$ & $9(56)$ & & & & \\
\hline High $(\geq 3)$ & $1(12)$ & $7(44)$ & & & & \\
\hline Chemotherapy & & & 0.2490 & & & \\
\hline Anthracycline & $2(25)$ & $1(6)$ & & & & \\
\hline Non-anthracyline & $6(75)$ & $15(94)$ & & & & \\
\hline Hemoglobin, g/L & $\begin{array}{l}135.5(114 \sim \\
142.5)\end{array}$ & $\begin{array}{l}127.0(114 \sim \\
144.5)\end{array}$ & 0.6205 & & & \\
\hline $\begin{array}{l}\text { Platelet count, } 10^{9} \\
/ \mathrm{L}\end{array}$ & $\begin{array}{l}201.0(164.5 \sim \\
235.8)\end{array}$ & $\begin{array}{l}206.0(172.8 \sim \\
296.5)\end{array}$ & 0.4435 & & & \\
\hline $\begin{array}{l}\text { Lymphocyte count, } \\
10^{9} / \mathrm{L}\end{array}$ & $\begin{array}{l}1.435(1.208 \sim \\
1.848)\end{array}$ & $\begin{array}{l}1.290(0.805 \sim \\
1.580)\end{array}$ & 0.4254 & & & \\
\hline $\begin{array}{l}\text { Lymphocyte } \\
\text { percentage, \% }\end{array}$ & $\begin{array}{l}28.60 \% \\
(18.90 \% \sim 31.05 \%)\end{array}$ & $\begin{array}{l}22.05 \% \\
(13.65 \% \sim 26.30 \%)\end{array}$ & 0.1199 & & & \\
\hline $\begin{array}{l}\text { Copies of Epstein- } \\
\text { Barr virus genome }\end{array}$ & $\begin{array}{l}32.70(10.30 \sim ~ \\
317.3)\end{array}$ & $\begin{array}{l}1420(155.3 \sim \\
35025)\end{array}$ & 0.0087 & 0.994 & $\begin{array}{l}0.840 \\
\sim \\
1.022\end{array}$ & 0.171 \\
\hline
\end{tabular}

Values are $\mathrm{n}(\%)$ or median (interquartile range)

ENKTL, extranodal natural killer/T-cell lymphoma; ECOG PS, Eastern Cooperative Oncology Group performance score; PINK-E,Prognostic Index of extranodal natural killer/T-cell lymphoma; OR, odd ratio; $95 \% \mathrm{Cl}, 95 \%$ 


\begin{tabular}{|c|c|c|c|c|c|c|}
\hline \multirow[t]{3}{*}{ Variable } & \multicolumn{2}{|l|}{ Univariate analysis } & \multirow[t]{3}{*}{$\mathbf{P}$} & \multicolumn{2}{|c|}{$\begin{array}{l}\text { Multivariate } \\
\text { analysis }\end{array}$} & \multirow[t]{3}{*}{$\mathbf{P}$} \\
\hline & $\begin{array}{l}\text { Complete } \\
\text { remission }\end{array}$ & $\begin{array}{l}\text { Other treatment } \\
\text { response }\end{array}$ & & OR & $95 \% \mathrm{Cl}$ & \\
\hline & $(n=8)$ & $(n=16)$ & & & & \\
\hline $\mathrm{Ki}-67, \%$ & $\begin{array}{l}47.50 \% \\
(41.25 \% \sim 55.00 \%)\end{array}$ & $\begin{array}{l}67.50 \% \\
(46.25 \% \sim 73.75 \%)\end{array}$ & 0.0304 & 0.871 & $\begin{array}{l}0.758 \\
\sim \\
1.002\end{array}$ & 0.054 \\
\hline $\begin{array}{l}\text { PD-1 level in tumor } \\
\text { tissues, \% }\end{array}$ & $\begin{array}{l}6.00 \% \\
(2.50 \% \sim 10.50 \%)\end{array}$ & $\begin{array}{l}0.00 \% \\
(0.00 \% \sim 9.75 \%)\end{array}$ & 0.2256 & & & \\
\hline $\begin{array}{l}\text { PD-L1 level in tumor } \\
\text { tissues, \% }\end{array}$ & $\begin{array}{l}35.50 \% \\
(10.00 \% \sim 59.00 \%)\end{array}$ & $\begin{array}{l}64.00 \% \\
(41.50 \% \sim 83.25 \%)\end{array}$ & 0.0218 & 0.926 & $\begin{array}{l}0.840 \\
\tilde{1} .022\end{array}$ & 0.126 \\
\hline \multicolumn{7}{|c|}{ Values are $\mathrm{n}(\%)$ or median (interquartile range) } \\
\hline \multicolumn{7}{|c|}{$\begin{array}{l}\text { ENKTL, extranodal natural killer/T-cell lymphoma; ECOG PS, Eastern Cooperative Oncology Group } \\
\text { performance score; PINK-E,Prognostic Index of extranodal natural killer/T-cell lymphoma; OR, odd } \\
\text { ratio; } 95 \% \mathrm{Cl}, 95 \%\end{array}$} \\
\hline
\end{tabular}

\section{Discussion}

Studies have found that in patients with follicular lymphoma, PD-1 is mainly expressed on CD4 + T lymphocytes in lymph node follicles ${ }^{[12]}$. Roncador G, García Verdes-Montenegro JF found that PD-1 is abnormally highly expressed in tissues of patients with angioimmunoblastic lymphoma (AITL) ${ }^{[14]}$, and other studies have reported the low level of PD-1 in tumor tissues of ENKTL patients ${ }^{[15]}$. However, this study found that PD-1 level in tumor tissues of ENKTL patients was significantly lower than that of DLBCL patients, and that PD-1 level in tumor tissues of ENKTL patients with B symptoms, increased LDH levels, and decreased hemoglobin concentration was lower. We believe that the low level of PD-1(+) infiltrating lymphocytes constitutes the immunosuppressive effect of lymphoma cells in tumor microenvironment and promotes tumor immune escape, from this perspective, the lower PD-1 level in ENKTL tumor tissue may be one of the possible reasons why ENKTL progresses faster than DLBCL.

In addition, Chen BJ, Chapuy B and other scholars have found that PD-L1 is expressed in $\mathrm{HL}, \mathrm{DLBCL}$, ENKTL and other lymphoma tissues, but no expression has been detected in Burkitt lymphoma [13], similar to this, this study is also found that PD-L1 is highly expressed in tumor tissues of ENKTL and DLBCL patients, it is suggested that the increased expression of PD-L1 is one of the possible reasons for the defect of cellular immune function in patients.

The efficacy-related analysis in ENKTL patients found that the LDH level, EBV-DNA copy number, Ki-67 index and PD-L1 level in tumor tissues will affect the efficacy of ENKTL patients, but are not independent 
factors, this suggests that the PD-1/PD-L1 signaling pathway may be involved in the disease progression of ENKTL patients, and is closely related to the patient's response to traditional chemotherapy.

In summary, the results of this study showed that the expression of PD-1/PD-L1 in the tumor tissues of patients is different in ENKTL and DLBCL patients, suggesting that the PD-1/PD-L1 signaling pathway has different roles in different lymphoma subtypes.

\section{Declarations}

\section{Ethics approval and consent to participate}

This study was approved by the Ethics Committee of West China Hospital of Sichuan University. Participants provided written consent for their anonymized clinical data to be used and published for research purposes.

\section{Data availability}

The datasets generated and analyzed in the current study are available from the corresponding author on reasonable request.

\section{Conflict of interest statement}

The authors declare no conflicts of interest.

\section{Funding}

This research was supported by a grant to C.X. from the Sichuan Science and Technology Program (2008FG0005).

\section{Acknowledgements}

C.X. initiated the project and designed the research. Y.F. and X.F. performed most experiments, analyzed the data, and drafted the manuscript. X.F. assisted in collecting clinical specimens. C.J., X.C., and X.Y. performed some experiments and provided critical suggestions.

\section{References}

1. Kwong YL, Chan AC, Liang R, et al. CD56+ NK lymphomas: clinicopathological features and prognosis. Br J Haematol 1997, 97(4), 821-829.

2. Keir ME, Butte MJ, Freeman GJ, et al. PD-1 and its ligands in tolerance and immunity. Annu Rev Immunol 2008, 26, 677-704.

3. Chen G, Huang AC, Zhang W, et al. Exosomal PD-L1 contributes to immunosuppression and is associated with anti-PD-1 response. Nature 2018, 560(7718), 382-386. 
4. Wu C, Zhu Y, Jiang J, et al. Immunohistochemical localization of programmed death-1 ligand-1 (PDL1) in gastric carcinoma and its clinical significance. Acta Histochem 2006, 108(1), 19-24.

5. Thompson RH, Kuntz SM, Leibovich BC, et al. Tumor B7-H1 is associated with poor prognosis in renal cell carcinoma patients with long-term follow-up. Cancer Res 2006, 66(7), 3381-3385.

6. Han L, Liu F, Li R, Li Z, Chen X, Zhou Z, Zhang X, Hu T, Zhang Y, Young K, Sun S, Wen J, Zhang M. Role of programmed death ligands in effective T-cell interactions in extranodal natural killer/T-cell lymphoma. Oncol Lett. 2014 Oct;8(4):1461-1469.

7. Sabattini E, Bacci F, Sagramoso C, et al. WHO classification of tumours of haematopoietic and lymphoid tissues in 2008: an overview. Pathologica 2010, 102(3), 83-87.

8. Cheson BD, Pfistner B, Juweid ME, et al. International Harmonization Project on Lymphoma. Revised response criteria for malignant lymphoma. J Clin Oncol. 2007, 25(5):579-86.

9. Kiyasu J, Miyoshi H, Hirata A, et al. Expression of programmed cell death ligand 1 is associated with poor overall survival in patients with diffuse large B-cell lymphoma. Blood. 2015, 126(19):2193-201.

10. Yang QP, Zhang WY, Yu JB, et al. Subtype distribution of lymphomas in Southwest China: analysis of 6,382 cases using WHO classification in a single institution. Diagn Pathol. 2011; 6:77.

11. Nagato T, Ohkuri T3, Ohara K, et al. Programmed death-ligand 1 and its soluble form are highly expressed in nasal natural killer/T-cell lymphoma: a potential rationale for immunotherapy, Cancer Immunol Immunother. 2017, 66(7):877-890.

12. Yang ZZ, Grote DM, Ziesmer SC, et al. PD-1 expression defines two distinct T-cell sub-populations in follicular lymphoma that differentially impact patient survival. Blood Cancer J. 2015, 5:e281.

13. Chen B J, Chapuy B, Ouyang J, et al. PD-L1 Expression Is Characteristic of a Subset of Aggressive Bcell Lymphomas and Virus-Associated Malignancies. Clinical Cancer Research. 2013,19(13):34623473.

14. Roncador G, García Verdes-Montenegro JF, et al. Expression of two markers of germinal center T cells (SAP and PD-1) in angioimmunoblastic T-cell lymphoma.Haematologica. 2007, 92(8):1059-66.

15. Jo JC, Kim M, Choi Y, et al. Expression of programmed cell death 1 and programmed cell death ligand 1 in extranodal NK/T-cell lymphoma, nasal type. Ann Hematol. 2017, 96(1):25-31.

\section{Figures}




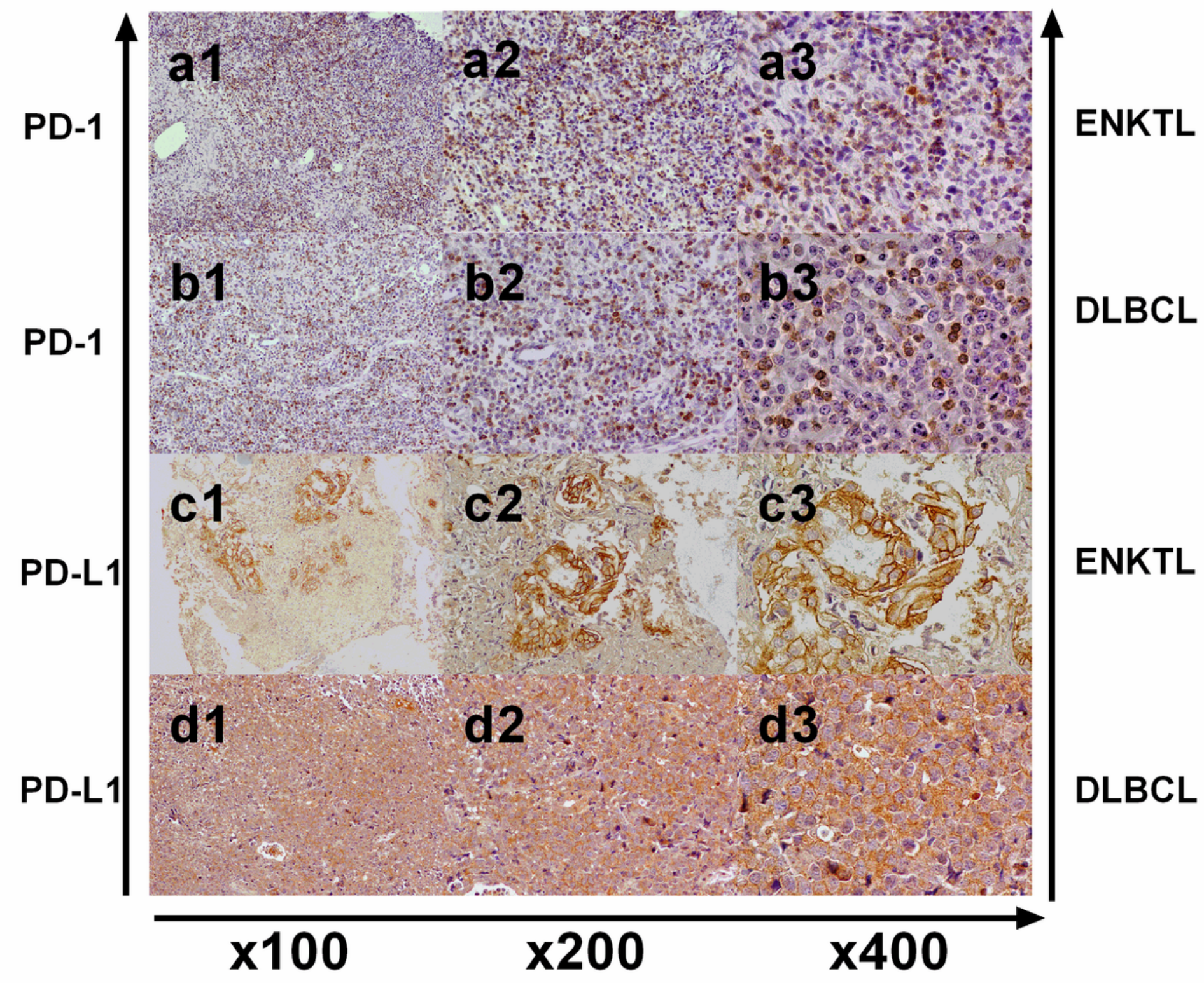

Figure 1

Immunohistochemical staining of PD-1 (a1-3, b1-3) and PD-L1 (c1-3, d1-3) under the microscope of 100, 200, 400 times. 
ENKTL

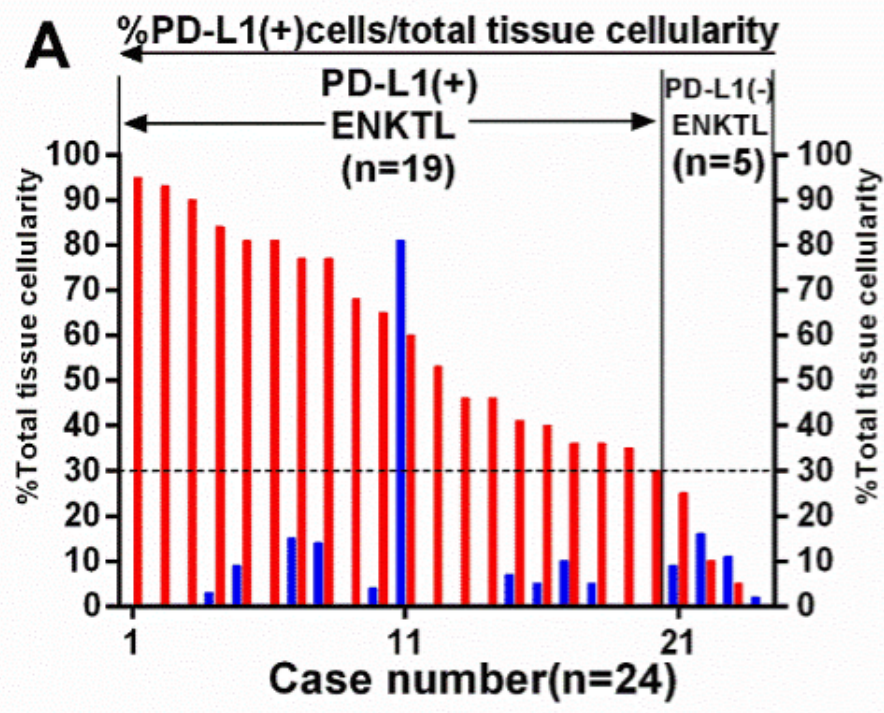

\%PD-L1(+) cell/total tissue cellularity $\%$ PD-1(+) cell/total tissue cellularity spearman $\mathrm{r}=-0.2786 \mathrm{P}=0.1874$
DLBCL
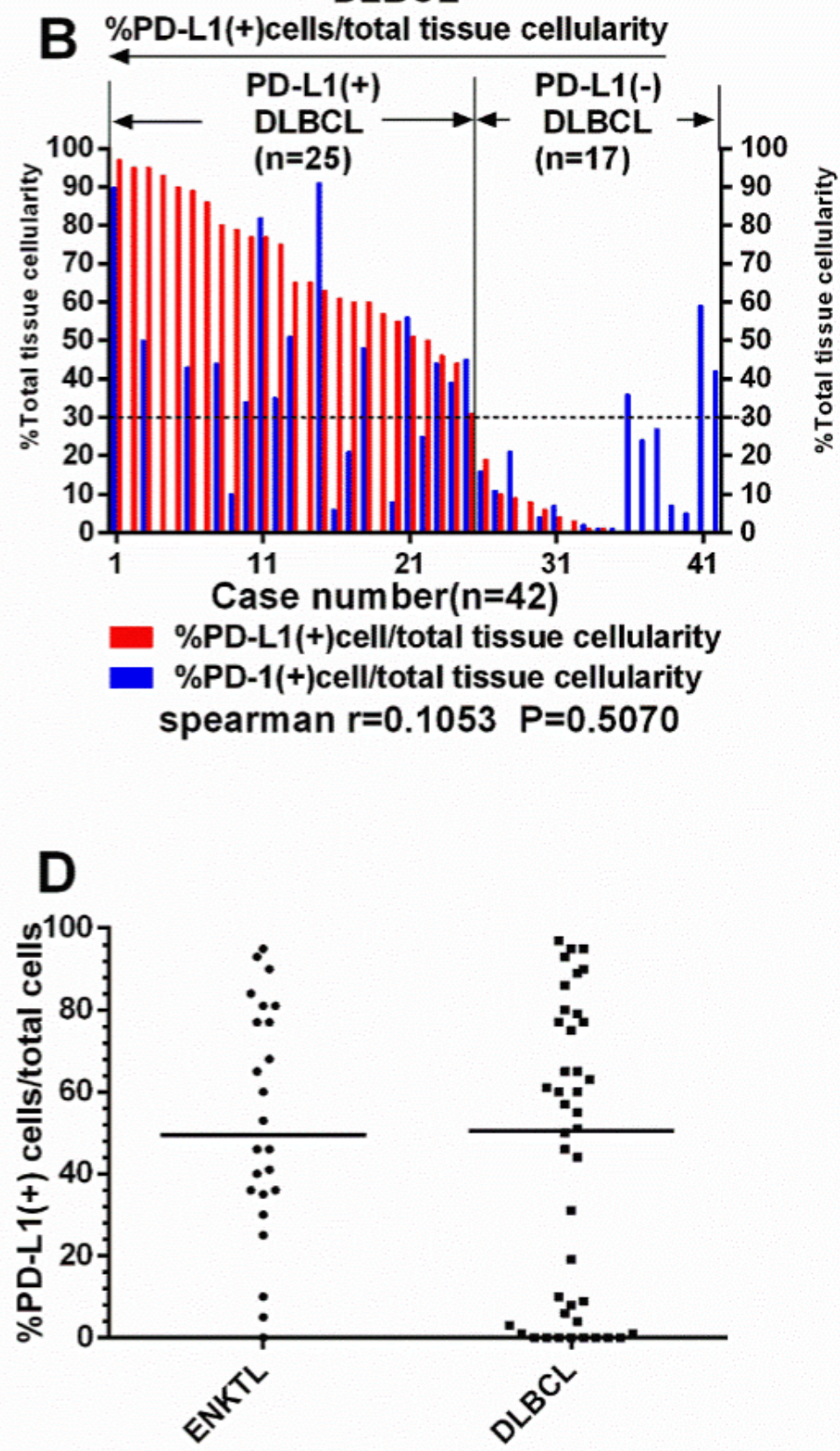

Figure 2

Details and correlation analysis of PD-1/PD-L1 expression in tumor tissues of ENKTL (A) and DLBCL (B) patients. No correlation was found between PD-1 and PD-L1 level from tumor tissues of ENKTL and DLBCL patients. Scatter plot of PD-1 (C) and PD-L1 (D) expression showed that PD-1 level in tumor tissues from ENKTL patients was lower than DLBCL. ${ }^{\star *} \mathrm{P}<0.01$. 


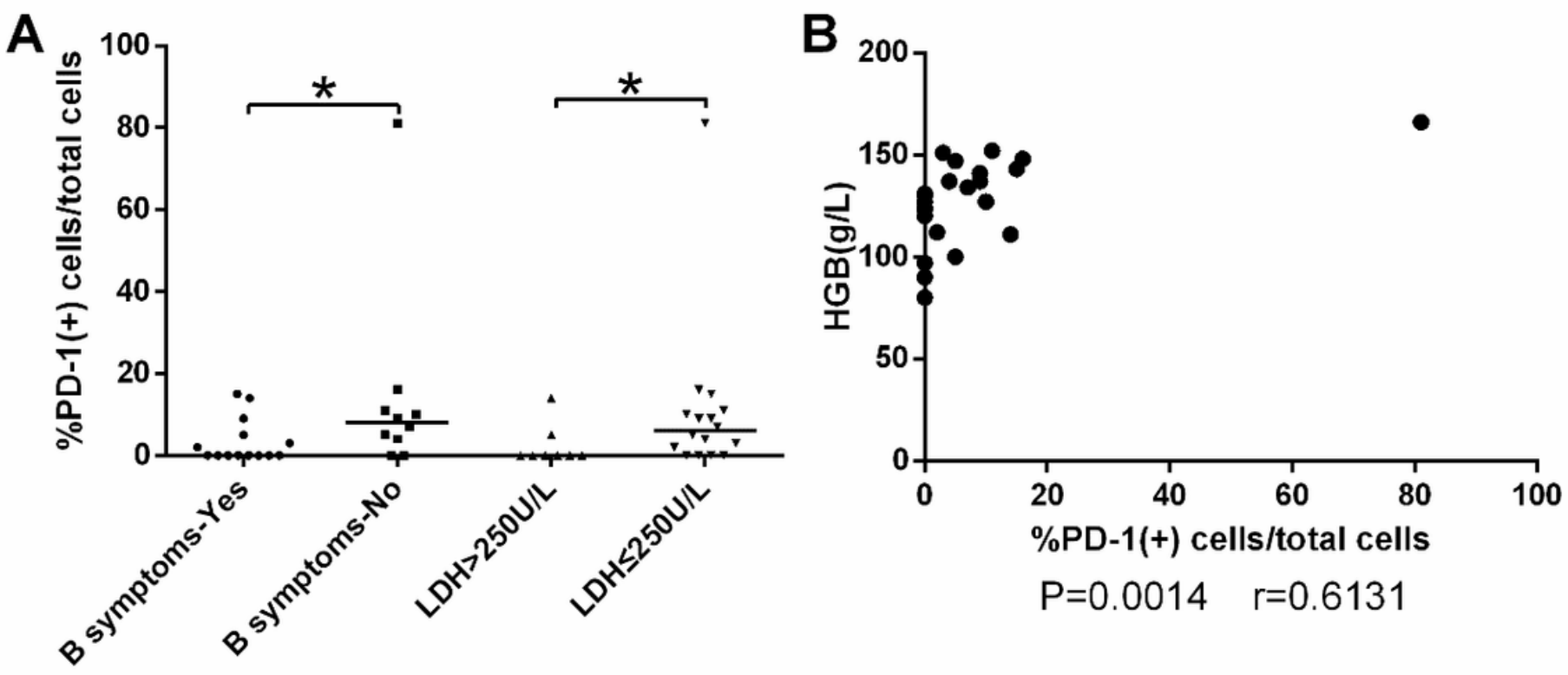

Figure 3

(A-B) In ENKTL patients, PD-1 level in tumor tissues varied with (A) B symptoms, (A) lactate dehydrogenase $(\mathrm{LDH})$ concentration, $(\mathrm{B})$ hemoglobin. ${ }^{*} \mathrm{P}<0.05$. 